\title{
Phylogeography and Population Structure of Tropical Trees
}

\author{
Christopher W. Dick
}

Published online: 13 March 2010

(C) Springer Science+Business Media, LLC 2010

This special issue of Tropical Plant Biology features research articles on phylogeography and population genetic structure of tropical trees. While studies throughout the 1990s examined the population genetics of a multitude of tropical tree species (reviewed in Dick et al. 2008), it is only in the past decade that researchers began to sample tropical trees across broad parts of their geographic ranges and use DNA markers to infer phylogeographic structure. There are many good reasons to focus evolutionary studies on tropical trees, not the least of which is the sheer number of species. Despite the fact that the vast majority of the world's tree diversity lies in the tropics, most of our genetic knowledge of trees comes from temperate and boreal forests, with a heavy emphasis on pines and oaks.

The processes that structure the genetic diversity of trees in tropical latitudes may differ in fundamental ways from those of temperate and boreal forests. There is evidence of a latitudinal gradient in phylogeographic and population genetic structure in plants and animals, with species near the equator showing higher levels of divergence (Dick et al.

\section{W. Dick $(\bowtie)$}

Department of Ecology and Evolutionary Biology,

University of Michigan,

830 North University Avenue,

Ann Arbor, MI 48109-1048, USA

e-mail: cwdick@umich.edu

\section{W. Dick}

University of Michigan Herbarium,

3600 Varsity Drive,

Ann Arbor, MI 48108-2287, USA

C. W. Dick

Smithsonian Tropical Research Institute,

P.O. Box 0843-03092, Balboa Ancón, Republic of Panama
2008; Eo et al. 2008; Martin and McKay 2004). This may be due to longer periods of climatic stability in the tropics, such that species may show range disjunctions around geological barriers that are much older than the Pleistocene vegetation changes that have shaped genetic patterns at higher latitudes. Relatively higher levels of population divergence in tropical trees may also be associated with the prevalence of animal pollination (Bawa 1990), which can produce clumped patterns of gene dispersal and strong genetic drift compared to wind pollinated temperate zone trees (Dick et al. 2008)

This special issue provides an in depth look at genetic structure and process in six tropical tree species, including three from tropical Africa and three from tropical America (see cover illustration). The studies relate to broader themes of botanical exploration, genetic resource management, and the elucidation of evolutionary processes.

\section{Botanical Exploration}

Woody plant diversity in the tropics may be a botanist's dream, but it can also be an identification nightmare. A single hectare of Amazon rain forest can harbor 300 tree species (Gentry 1986) and up to 22,500 tree species are estimated to exist in the Neotropical moist forest biome (Fine and Ree 2006). Compare this to fewer than 200 native tree species in continental Europe. Systematists have engaged in the process of describing tropical plant diversity for more than two centuries, yet many species remain to be described. Prance et al. (2000) estimate that one in 100 herbarium specimens from remote tropical forests represent species that are new to science. The few specimens are often inadequate to describe taxonomic boundaries or geographic ranges of new species. The dearth of herbarium 
collections is exacerbated by a global decline in taxonomic expertise, as major universities have replaced systematists with molecular biologists and downsized herbaria.

Population genetics can contribute to botanical exploration through its focus on intraspecific variation, which may include geographic populations, cryptic species, or hybrid intermediates. In their study of chloroplast DNA (cpDNA) variation in the African rain forest tree Greenwayodendron suaveolens (Engl. \& Diels) Verdc. (Annonaceae), Dauby et al. (2010) found fixed haplotype differences in two sympatric varieties (var. gabonica and var. suaveolens). This suggests that the varieties are reproductively isolated, and that var. gabonica should be elevated to the rank of species under a biological species concept. The study shows how phylogeographic data can be used to flag "cryptic species" for closer taxonomic scrutiny (Dick and Kress 2009; Duminil et al. 2006) and help to define species boundaries.

\section{Genetic Resource Management}

Phylogeographic techniques can be used to explore the evolutionary diversity of economically important species, with relevance to conservation and management. Mahogany, Swietenia macrophylla King (Meliaceae), is the most economically important native timber tree of the American tropics, and is listed in CITES after more than 200 years of predatory logging. Despite the species' value and silvicultural potential, previous studies have characterized genetic variation over relatively small parts of the overall range. In this issue, Lemes et al. (2010) present a cpDNA phylogeographic analysis of mahogany from natural populations ranging from Mexico to Panama, in Central America, and across 2,100 km of the southern arc of the Amazon basin. Their data show a strong phylogeographic break between Central and South America, high levels of population differentiation in the Amazon basin and, in contrast, relatively low differentiation across Central America.

These data may prove useful for silviculture, because geographic variation in mahogany has been linked to adaptive traits such as growth rate and resistance to shoot boring insects. The provenance trials of mahogany at the CATIE research institute, in Costa Rica, consist entirely of Central American trees. The Lemes study suggests that additional trait variation may be encountered in South American populations. Furthermore, because there were so many private haplotypes in the Brazilian populations, the cpDNA markers can be used to verify timber provenance within Brazil and identify mahogany that has been illegally extracted from protected areas. The use of genetic markers for timber tracking has been facilitated by recent technical advances in DNA extraction from wood samples (Deguilloux et al. 2002).
Working in the arid and semi-arid landscape of east Africa, Omondi et al. (2010) examined phylogeographic structure in Acacia senegal (L) Willd. (Fabaceae) across Kenya. Acacia senegal is a nitrogen-fixing legume tree, whose sap has for centuries been harvested for gum arabic, which is an emulsifying agent used in paints, food and soft drinks. Acacia senegal is also useful for land reclamation and its protein-rich leaves serve as fodder for cattle. The study found two geographic populations located in the rift valley and in eastern Kenya. This data can form the basis for establishing provenance trials to examine silvicultural variation in this high potential species.

A different kind of management question regards the genetic quality of seeds used in ecological restoration. Davies et al. (2010) examined genetic consequences of colonization of abandoned pasture by Vochysia ferruginea Mart., which is a long-lived tree that colonizes disturbed areas in Central America. Like other species in the family Vochysiaceae, V. ferruginea tolerates poor soils and aluminum toxicity found in pasture and other degraded tropical landscapes. The authors examined the kinship and fine scale spatial genetic structure of colonizing seedlings, and found that remnant old growth forest trees contributed substantially to the genetic diversity of the colonizing populations. Without these old seed trees scattered in the landscape, $V$. ferruginea would likely suffer reduced genetic diversity and inbreeding during the colonization process.

\section{Evolutionary Processes}

Phylogeographic data can be used to infer the geographic and ecological processes that lead to population divergence and speciation. The first step is to distinguish divergence due to genetic drift and dispersal, under an isolation by distance model, from divergence caused by geographic barriers (Guillot et al. 2009). Hardesty et al. (2010) used nuclear microsatellite DNA to distinguish these two processes by testing for differences in population differentiation under a stepwise mutation model $\left(R_{\mathrm{ST}}\right)$ and an infinite allele model $\left(F_{\mathrm{ST}}\right)$. Whereas $F_{\mathrm{ST}}$ measures the differentiation as the balance of drift and gene flow, $R_{\mathrm{ST}}$ also captures the contribution of accumulated mutations to the population divergence (Hardy et al. 2003). In their study of the Neotropical forest tree Simarouba amara Aubl. (Simaroubaceae), Hardesty and colleagues found significant effects of mutations, and hence phylogeographic structure, in populations sampled east and west of the northern Andes, such that populations on either side of the Andes in Ecuador and separated by only $200 \mathrm{~km}$ were more highly differentiated than populations separated by more than $2,000 \mathrm{~km}$ in the Amazon basin. The impact of the northern Andes on phylogeographic structure in Simarouba 
amara has been shown for a handful of other lowland animal and plant species (e.g. Burney and Brumfield 2009; Dick and Heuertz 2008) and is likely to occur in hundreds of lowland species with the cross-Andean geographic distribution.

Whereas the northern Andes and other tropical mountains rose to modern elevations in the late Cenozoic (Miocene-Pliocene), some of the most severe vegetation changes in tropical regions occurred during glacial and interglacial phases of the Pleistocene. The cool and dry glacial periods severely constricted broadleaf forests in North America and Europe, and shaped the genetic structure of tree species in both of these continents. The impact of Pleistocene climates on tropical forests, however, remains poorly understood because of a very sparse palynological record. Two of the papers in this issue attempt to interpret Pleistocene forest history on the basis of the genetic structure of rain forest trees. Lowe et al. (2010) matched spatial distribution of cpDNA and nuclear DNA haplotypes with proposed Pleistocene forest refuges for the bush mango, Irvingia gabonensis Aubry-Lecomte ex O'Rorke. Dauby et al. (2010) found a north-south phylogeographic disjunction in Greenwayodendron suaveolens that may have been caused by Pleistocene forest fragmentation. These two studies are among the first phylogeographic studies of Central African rain forest trees.

\section{Future Directions}

Thousands of tropical tree species have yet to be sequenced for a single gene, and even relatively common trees harbor high levels of geographic variation that remains uncharacterized. Range-wide studies of tropical trees pose many logistic challenges, such as obtaining samples from rapidly dwindling forests in countries that pose restrictions on forest access and genetic research. Such studies require strong international collaborations and agreements about transfer of materials, even for non-commercial research. As noted by Lowe et al. (2010) future studies are also likely to obtain much greater genomic sampling by taking advantage of next generation sequencing technology.

With the accumulation of studies of individual species and increased genomic sampling, it will become possible to perform multi-species tests of shared biogeographic history (e.g. Hickerson et al. 2006). Such methods have not been widely applied to plants due to the slow rate of cpDNA evolution and the lack of homologous nuclear genomic markers for diverse plant lineages. It should be easier to detect relatively old events (such as impacts of mountains) on widespread species because older events are associated with higher levels of DNA sequence divergence. Future studies should also be able to more specifically characterize geographic patterns in adaptive genetic variation. The present studies lay out hypothesis-testing frameworks in which such future studies will be conducted.

\section{References}

Bawa KS (1990) Plant-pollinator interactions in tropical rainforests. Annu Rev Ecol Syst 21:399-422

Burney CW, Brumfield RT (2009) Ecology predicts levels of genetic differentiation in Neotropical birds. Am Nat 174:358-368

Dauby G, Duminil J, Heuertz M, Hardy OJ (2010) Chloroplast DNA polymorphism and phylogeography of a Central African tree species widespread in mature rainforests: Greenwayodendron suaveolens (Annonaceae). Tropical Plant Biol 3(1):4-13

Davies SJ, Cavers S, Finegan B, Navarro C, Lowe AJ (2010) Genetic consequences of multigenerational and landscape colonisation bottlenecks for a neotropical forest pioneer tree, Vochysia ferruginea. Tropical Plant Biol 3(1):14-27

Deguilloux MF, Pemonge MH, Petit RJ (2002) Novel perspectives in wood certification and forensics: dry wood as a source of DNA. Proc R Soc Lond B Biol Sci 269:1039-1046

Dick CW, Heuertz M (2008) The complex biogeographic history of a widespread tropical tree species. Evolution 62:2760-2774

Dick CW, Kress WJ (2009) Dissecting tropical plant diversity with forest plots and a molecular toolkit. Bioscience 59:745-755

Dick CW, Hardy OJ, Jones FA, Petit RJ (2008) Spatial scales of pollen and seed-mediated gene flow in tropical rain forest trees. Tropical Plant Biology 1:20-33

Duminil J, Caron H, Scotti I, Cazal SO, Petit RJ (2006) Blind population genetics survey of tropical rainforest trees. Mol Ecol 15:3505-3513

Eo SH, Wares JP, Carroll JP (2008) Population divergence in plant species reflects latitudinal biodiversity gradients. Biol Lett 4:382-384

Fine PVA, Ree RH (2006) Evidence for a time-integrated species-area effect on the latitudinal gradient in tree diversity. Am Nat 168:796-804

Gentry AH (1986) Tree species richness of upper Amazonian forests. PNAS 85:156-159

Guillot G, Leblois R, Coulon A, Frantz AC (2009) Statistical methods in spatial genetics. Mol Ecol 18:4734-4756

Hardesty BD, Dick CW, Hamrick JL, et al (2010) Geographic influence on genetic structure of the widespread Neotropical tree, Simarouba amara (Simaroubaceae). Tropical Plant Biol 3(1):28-39

Hardy OJ, Charbonnel N, Fréville H, Hueuertz M (2003) Microsatellite allele sizes: a simple test to assess their significance on genetic differentiation. Genetics 163:1467-1482

Hickerson MJ, Dolman G, Moritz C (2006) Comparative phylogeographic summary statistics for testing simultaneous vicariance. Mol Ecol 15:209-223

Lemes MR, Dick CW, Navarro C, et al (2010) Chloroplast DNA microsatellites reveal contrasting phylogeographic structure in mahogany (Swietenia macrophylla King, Meliaceae) from Amazonia and Central America. Tropical Plant Biol 3(1):40-49

Lowe AJ, Harris D, Dormontt E, Dawson IK (2010) Testing putative African tropical forest refugia using chloroplast and nuclear DNA phylogeography. Tropical Plant Biol 3(1):50-62

Martin PR, McKay JK (2004) Latitudinal variation in genetic divergence of populations and the potential for future speciation. Evolution 58:938-945

Omondi SF, Kireger E, Dangasuk OG, et al (2010) Genetic diversity and population structure of Acacia senegal (L.) Willd. in Kenya. Tropical Plant Biol 3(1):63-74

Prance GT, Beentje H, Dransfield J, Johns R (2000) The tropical flora remains undercollected. Ann Mo Bot Gard 87:67-71 